\title{
Performance Evaluation of Regional Fiscal Expenditure for Energy Conservation and Environmental Protection Based on a Panel Data Model - a Case in Shandong Province, China
}

\author{
Huilu Yu ${ }^{1 * \#}$, Suocheng Dong ${ }^{2}$, Hongping Fei ${ }^{3 \#}$, Fei $\mathrm{Li}^{2 * *}$, \\ Xiaorong Guan', Shuguang Jiang ${ }^{1}$
}

${ }^{1}$ School of Resources and Environmental Engineering, Ludong University, Yantai 264025, China ${ }^{2}$ Institute of Geographic Sciences and Natural Resources Research, Chinese Academy of Sciences,

11A Datun Road, Anwai, Chaoyang District, Beijing 100101, China

${ }^{3}$ Research Institute of Industrial and Technological Economy, Macroeconomic Research Institute of China, Beijing 100038, China

Received: 10 June 2021

Accepted: 12 June 2021

\begin{abstract}
Making use of econometric models in Shandong province of China, the paper verifies a method which can calculate the scale of positive externality measured in currency caused by enterprises' activity, and evaluates the performance of government fiscal expenditure for energy conservation and environmental protection in internalizing the positive externality of enterprises' activity in industrial system. Firstly, with the aid of the economic implications of econometric model parameters and the coefficient of determination, we separate the share of resource saving and the pollutant emission reduction caused by government fiscal expenditure from the total industrial resource saving and pollutant emission reduction; secondly, the environmental value of unit pollutant emission reduction and unit resource saving is estimated by using the data of the amount of pollutants removed from the regional industrial system and the operating costs of the relevant facilities; thirdly, with the aid of data on this expenditure and environmental value of unit pollutant emission reduction and unit resource saving, we monetize the scale of positive externalities of the entire regional industrial system; finally, the performance evaluation indicator is constructed to evaluate the performance of government fiscal expenditure for energy conservation and environmental protection in Shandong Province and typical municipal governments. The paper draws several conclusions: It is reasonable to use the internalization degree of positive externalities as the performance evaluation key indicator of government fiscal expenditure for energy conservation and environmental protection; there is a problem of low performance
\end{abstract}

\footnotetext{
"The authors contributed equally to this study.

*e-mail: yuhuilu73@163.com

**e-mail: 1f@igsnrr.ac.cn
} 
in regulating the positive externalities of enterprises in Shandong Province; the performance level can be improved by adjusting the expenditure structure of energy conservation and environmental protection funds; environmental values of unit pollutant emission reduction and unit resource conservation have obvious spatial differences, which has a significant impact on fiscal expenditure performance for energy conservation and environmental protection.

Keywords: positive externality, fiscal expenditure for energy conservation and environmental protection, environmental value, performance evaluation

\section{Introduction}

In order to coordinate the relationship between economic development and environmental protection, the Ministry of Finance clearly defined public environmental expenditures in the government reform of revenue and expenditure classification implemented in 2007 in China. From 2007 to 2011, it was listed in the name of environmental protection in the main items of central and local government fiscal expenditure; after 2012, environmental protection expenditure was renamed as energy conservation and environmental protection expenditure. From 2007 to 2018, China's public environmental expenditure increased nearly sixfold, from US\$15.113 billion in 2007 to US\$95.576 billion in 2018, and its share of GDP (Gross Domestic Product) increased from $0.45 \%$ to $0.70 \%$. This expenditure is playing an increasingly important role in the improvement of China's environmental quality (Table 1). There is now more literature about fiscal environmental expenditure, which has become a hot spot of academic research.

With "Fiscal Expenditure" and "Environment Protection" as the key words, and the research literatures limited to articles published in the past 5 years, we searched the Web of Science abstract database and obtained 25 articles written in English, all of which are far from the theme of "performance evaluation of fiscal environmental expenditure". Therefore, we mainly analyzed the Chinese literature on the subject. Taking CNKI periodical full-text database as the retrieval source, we searched the Chinese literature from 2007 to 2019. Firstly, the search was conducted with the subject term "environmental protection". Secondly, the papers obtained by first step were then further refined by the subject term "financial expenditure", resulting in a total of 599 journal articles and doctoral or master's theses. Finally, these papers were manually screened, based on whether the research content revolves around public environmental expenditure and its impact on environmental quality, and a total of 118 articles were obtained. Generally speaking, these research literature can be divided into three categories: the first category is research on the effect of government public environmental expenditure, a total of 62 articles, including 24 journal articles, and 28 doctoral or master's theses; the second category is composed of 47 articles, including 24 journal articles and 23 doctoral or master's theses, evaluate the efficiency of public environmental expenditure in government finance; the third category consists of 10 articles describing the development course and policy of public environmental expenditure

Table 1. Abbreviations of professional terms.

\begin{tabular}{|c|c|}
\hline Professional terms & Abbreviation \\
\hline Fiscal expenditure for energy conservation and environmental protection & FEECEP \\
\hline Resource saving and pollutant emission reduction & RSPER \\
\hline Chinese Social Sciences Citation Index & CSSCI \\
\hline Data Envelopment Analysis & DEA \\
\hline Chemical oxygen demand & COD \\
\hline Nitrogen oxide & NOx \\
\hline Research and development & $\mathrm{R} \& \mathrm{D}$ \\
\hline Sulfur dioxide & $\mathrm{SO} 2$ \\
\hline China National Knowledge Internet & CNKI \\
\hline Life Cycle Assessment & LCA \\
\hline Net present value & NPV \\
\hline Gross Domestic Product & GDP \\
\hline
\end{tabular}


Table 2. Distribution of research methods of journal articles and doctoral or master's theses focusing on the effect of government fiscal expenditure on environmental protection from 2007 to 2019.

\begin{tabular}{|c|c|c|c|c|}
\hline \multirow{2}{*}{ Category } & \multirow{2}{*}{ Paper level } & \multicolumn{2}{|c|}{ Econometric model method } & \multirow{2}{*}{ Other methods } \\
\cline { 2 - 5 } & & Provincial (panel) data & Prefecture-cities (panel) data & 0 \\
\hline \multirow{3}{*}{ Journal papers } & CSSCI & 9 & 0 & 0 \\
\cline { 2 - 5 } & Core Journals & 3 & 3 & 8 \\
\cline { 2 - 5 } & Other Journals & 1 & 1 & 1 \\
\hline \multirow{2}{*}{ Degree thesis } & Ph.D & 5 & 2 & 13 \\
\cline { 2 - 5 } & Master & 16 & $6 / 62$ & $22 / 62$ \\
\hline
\end{tabular}

Annotation: Core Journals are journals incorporated in the source journal of Peking University Chinese Core Journals Overview.

in developed countries. This third category of literature focuses on the experiences of developed countries in the area of public environmental expenditure from which China can learn. This kind of literature deviates greatly from the topic discussed in this paper, so it was not analyzed. Thus, to analyze the shortcomings of the current research, the following is based on the first and second types of literature.

The first type of literature focuses on the mechanism of environmental quality optimization, and mainly discusses the role of public environmental expenditure in regional energy conservation and pollutant emission reduction. This kind of literature mostly uses econometric analysis methods, and the analysis samples are mainly provincial panel data (Table 2).

Most research results show that, overall, government environmental expenditure has a positive effect on improving environmental quality, and there are noticeable regional differences [1-5]. For example, Zhu Xiaohui and $\mathrm{Lu}$ Yuanquan constructed the pollution control coefficient of regional environmental and fiscal policy, and calculated the values of every provincial region in China, with which thirty provincial administrative regions of the country were divided into two types of regions, then estimates econometric models respectively to analyze the effects of environmental fiscal policy, environmental tax policy, and environmental decentralization on pollution control. The results show that the fiscal expenditure on environmental protection has a significant effect of pollution control, and that environmental decentralization is not conducive to the reduction of pollutants [6]. Zang Chuanqin and Chen Meng estimated the dynamic panel model using the panel data of 30 provinces in China, and made an empirical analysis on the effect of FEECEP. It was concluded that fiscal expenditure for environmental protection has a positive direct and indirect impact on the improvement of environmental quality. Namely, environmental quality can be improved by guiding social capital to invest in the field of environmental protection [7].
The econometric model establishes the quantitative relationship between the explanatory variables and the explained variable; the parameters imply the meaning of "average" when describing the relationship between the explained variable and the explanatory variables [8]. Due to the huge gap in the level of development, even if 30 provincial administrative regions are further subdivided into eastern, central, and western regions, there will be a big deviation from the reality using the estimated model parameters to explain the development of a specific province. Therefore, relatively speaking, if the research scope is defined within a specific province, and the data of prefecture-level cities are used for quantitative regression analysis, the application value of model parameters is greater [5,9]. In addition, scholars' use of econometric model parameters is often limited to explaining the economic meaning of the parameter's sign, and analyzing the elasticity of the explained variable to the variation of explanatory variable, and the potential values of the model parameters are not sufficiently explored. At the same time, scholars often employ pollutant emission data to construct a composite index or DEA evaluation results as explained variable when estimating econometric models [10], so that the explained variable only has symbolic meaning, and the economic implication of the model parameters becomes more abstract, and its policy guiding significance is greatly reduced.

The second type of literature focuses on performance evaluation, which mainly discusses the performance level of regional fiscal environmental expenditure, its spatial difference and influencing factors [11, 12]. The DEA method, which accounts for $74 \%$ of the total literatures, plays a leading role in this kind of research (Table 3). The DEA method defines the most efficient decision-making unit as a technical frontier by a linear programming method and analyzes the relative efficiency of other decision-making units according to this technical frontier [13]. The application values of the conclusions obtained by DEA method via horizontal comparison and vertical comparison are limited. Horizontal comparison can only find 
Table 3. Research method distribution of journal articles and theses with the theme of efficiency evaluation of FEECEP from 2007 to 2019.

\begin{tabular}{|c|c|c|c|c|}
\hline \multirow{2}{*}{ Category } & \multirow{2}{*}{ Paper level } & \multicolumn{2}{|c|}{ DEA method } & \multirow{2}{*}{ Other methods } \\
\cline { 2 - 5 } & & Provincial (panel) data & Prefecture-cities (panel) data & 4 \\
\hline \multirow{3}{*}{ Journal papers } & CSSCI & 7 & 1 & 1 \\
\cline { 2 - 5 } & Core Journals & 0 & 0 & 2 \\
\cline { 2 - 5 } & Other Journals & 6 & 3 & 1 \\
\hline \multirow{2}{*}{ Dissertation } & Ph.D & 3 & 0 & 4 \\
\hline & Master & 7 & 7 & $11 / 46$ \\
\hline
\end{tabular}

Annotation: Core Journals are journals incorporated in the source journal of Peking University Chinese Core Journals Overview.

the efficiency gap of specific decision-making unit compared with the best decision-making unit [14, 15]. Vertical comparison can only see the general developing trend of specific decision-making unit's efficiency [16]. The DEA method has a strong assumption that all decision-making units satisfy the isomorphism [17], but scholars often weaken or even ignore this application condition in practical application. Due to the huge inter-provincial gap in China's development level and development path, the credibility of the results is strongly affected by the DEA analysis using national provincial environment and economic data. In addition, scholars almost seldom take into account the environmental value of energy conservation and pollutant emission reduction, which also to some extent reduces the utility of the efficiency value calculated by the DEA method.

There are many defects in the current research methods on the efficiency evaluation of the government fiscal environmental expenditure; for example, the geographical scale of sample data is too large, the economic meaning of the estimated parameters of the econometric model has not been sufficiently explored, and the role of the environmental value of energy conservation and pollutant emission reduction in the efficiency evaluation has been ignored. In particular, it does not make full use of the role of evaluation criteria that the externality theory should play in the efficiency evaluation of fiscal environmental expenditure.

Aiming at compensating for the defects of the current research, this paper takes the economic activities with positive externalities such as RSPER of 17 prefecture-level cities in Shandong Province of China as the research object, evaluates the performance of government fiscal environmental expenditure based on the internalization degree of externality, which incorporates the environmental value factors of RSPER. It is expected that the research conclusions can provide a theoretical reference for improving the performance of government fiscal environmental expenditure.

\section{Methodology}

\section{Taking the Degree of Positive Externality Internalization as the Theoretical Basis of Performance Evaluation Criteria}

We assume that the positive externalities of enterprise activity measured in currency mainly include the environmental values of resource saving and pollutant emission reduction. The environmental values of energy saving are equal to the environment loss caused by pollutants and greenhouse gas emitted by the same amount of energy consumption. As the pollutant emission reduction effect of energy saving has been embodied in the decline of pollutant emission intensity per unit of industrial value-added per year, when calculating the environmental values of energy saving, we only calculate the environmental values of greenhouse gas emission reduction in order to avoid environmental values of pollutant emission reduction being calculated twice. The environmental values of water saving can be regarded as reducing the discharge of water pollutants, and the amount is equal to the content of pollutants in the same amount of industrial wastewater that meets national standards.

This study takes the internalization degree of positive externality as the performance evaluation criterion of government fiscal expenditure for energy conservation and environmental protection. We define that the internalization degree is the ratio of the monetization positive externality of enterprises' activity to government fiscal expenditure for energy conservation and environmental protection.

We must first obtain the amount of resource saving and pollutant emission reduction caused by this expenditure. The analysis method of econometrics can provide method guidance for calculating the amount of resource conservation and emission reduction caused by this expenditure. 


\section{The Economic Implication and Application of the Econometric Model}

In the estimated econometric model that relevant data are all processed in logarithm, the meaning of the parameter before an explanatory variable is the elasticity of the explained variable to the change rate of the explanatory variable. That is, obtaining the change rate of an explanatory variable, the change rate of explained variable caused by the explanatory variable's change can be obtained under the condition that other variables remain unchanged. In turn, the relationship between explained variable and explanatory variables is still true within the observation period. On the basis of knowing the change rate of the explained variable, the share of change caused by a certain explanatory variable can be calculated. But the effect of the change of explanatory variables is a partial effect, which has strong constraints [8]; that is, it is necessary to ensure that other conditions remain unchanged, which greatly limits the application value of the parameters. On the basis of the relative clarity of the mechanism of pollutant emission reduction, we employ a set of methods to overcome the inherent limitations of the partial effect of the econometric model parameters. Relying on the model parameters' meaning of elasticity, the amounts of resource saving and pollutant emission reduction caused by government expenditure for energy conservation and environmental protection can then be calculated.

\section{Variable Selection and Model Assumption}

\section{Variable Selection and Data Description}

This study takes the FEECEP of 17 prefecturelevel cities in Shandong Province from 2007 to 2017 as the research object. We assume that it is impossible to judge how much fiscal resources have been invested respectively in every fields of industrial pollutant emission reduction because that the current FEECEP in Shandong Province's prefecture-level cities does not have detailed sub-sector data. The emission reduction effect on various industrial pollutants can only be estimated according to the overall data of this expenditure.

Assuming that government FEECEP was allocated into $m$ kinds of industrial pollutant emission reduction, and the structure of government expenditure in this field is relatively stable during the study period, the quantitative relationship between pollutant emission intensity per unit of industrial value added or resource consumption intensity and government FEECEP can be estimated. We can monetize the environmental value of resource saving and pollutant emission reduction caused by this expenditure, as shown in Formula (1).

$$
Q_{i, t}=\sum_{j=1}^{m}\left(e x_{i, j, t} \times p_{i, j}\right)
$$

$Q_{i, t}$ is the environmental value of resource saving and emission reduction caused by government FEECEP in the $t$-period of city $i, e x_{i, j, t}$ is the amount of the $j$ kind of pollutant emission reduction or resource saving caused by government FEECEP in the $t$-period of city $i$, and $p_{i, j}$ is the unit environmental value produced by $j$ kind of pollutant or resource when its emission was reduced or its consumption was saved in city $i$.

The data used in this study come from several types of statistical yearbooks in recent years, including China Environmental Statistics Yearbook, China Environmental Statistics Yearbook, Shandong Statistical Yearbook, and prefecture-level city's statistical yearbooks in Shandong province. Due to the absence of statistics, the sample cities of the nitrogen oxide emission data include nine prefecture-level cities of Jinan, Qingdao, Zibo, Zaozhuang, Yantai, Weifang, Jining, Tai'an, and Rizhao. Other data include all 17 prefecture-level cities in Shandong province. it means that in addition to the above-mentioned nine cities, data also come from prefecture-level cities of Dongying, Weihai, Laiwu, Linyi, Dezhou, Liaocheng, Binzhou, and Heze.

Table 4. Comprehensive utilization rates of general industrial solid waste in Shandong province in recent years.

\begin{tabular}{|c|c|c|c|c|c|c|c|c|c|}
\hline Year & 2009 & 2010 & 2011 & 2012 & 2013 & 2014 & 2015 & 2016 & 2017 \\
\hline Comprehensive utilization rate/\% & 98 & 95 & 95 & 93 & 94 & 96 & 92 & 84 & 80 \\
\hline
\end{tabular}

Table 5. Total investment amount and structure of industrial pollution prevention and control in Shandong province in recent years.

\begin{tabular}{|c|c|c|c|c|}
\hline Year & $\begin{array}{c}\text { Annual completed investment / } \\
\text { thousand US\$ }\end{array}$ & $\begin{array}{c}\text { Disposal of waste gas } \\
/ \%\end{array}$ & $\begin{array}{c}\text { Disposal of wastewater } \\
/ \%\end{array}$ & $\begin{array}{c}\text { Disposal of solid waste } \\
/ \%\end{array}$ \\
\hline 2014 & 21497.08 & 90.46 & 5.83 & 0.59 \\
\hline 2015 & 14356.05 & 82.64 & 7.02 & 3.48 \\
\hline 2016 & 19183.55 & 76.48 & 9.1 & 2.3 \\
\hline 2017 & 17164.64 & 71.92 & 9.34 & 0.08 \\
\hline
\end{tabular}


The general comprehensive utilization rates of industrial solid waste in prefecture-level cities in Shandong province have reached a very high level (Table 4), and the investment scale in the field of solid waste disposal is very small compared with that of waste gas and wastewater (Table 5), so the positive externalities involved in this study do not take the emission reduction of solid waste into account.

Taking into account the availability of data and the governmental emphasis on different types of industrial pollutants, this study selects the consumption amounts of energy and water, the emission amounts of sulfur dioxide, nitrogen oxides, smoke and dust, chemical oxygen demand, greenhouse gas (carbon dioxide) and ammonia nitrogen as the objects of analysis.

The symbols and meanings of the explanatory variables and the explained variables are shown in Table 6.

Because the econometric model requires that the data must be stationary when doing the regression analysis between the explained variables and the explanatory variables, the series data are logarithmized. In order to eliminate the influence of price fluctuations, the industrial value added data, FEECEP, industrial enterprises expenditure on R\&D, and other data used in this paper are all processed by the GDP deflator. The GDP deflator refers to the ratio of the nominal GDP of that year to the GDP calculated in 2000 constant price.

\section{Model Hypothesis and Basic Models}

The purpose of government expenditure for energy conservation and environmental protection is to save resources and reduce pollutant emissions, so there is a negative correlation between it and resource consumption intensity or pollutant emission intensity. Scientific and technological progress can promote resource saving and pollutant emission reduction, so it is also negatively correlated with resource consumption intensity or pollutant emission intensity.

Table 6. Explanatory variables and explained variables.

\begin{tabular}{|c|c|c|c|}
\hline Category & Variable & Symbol & Description \\
\hline \multirow{7}{*}{$\begin{array}{l}\text { Explained } \\
\text { variable }\end{array}$} & $\begin{array}{c}\text { Energy consumption intensity / tce / } \\
\text { thousand US\$ }\end{array}$ & LNenergy $_{\mathrm{t}}$ & $\begin{array}{c}\text { Industrial energy consumption amount/ values added of industrial } \\
\text { enterprises above designated size (take the logarithm) }\end{array}$ \\
\hline & $\begin{array}{c}\text { Water consumption intensity / ton / } \\
\text { thousand US\$ }\end{array}$ & $\mathrm{LNh} 2 \mathrm{o}_{\mathrm{t}}$ & $\begin{array}{l}\text { Industrial water consumption amount / values added of industrial } \\
\text { enterprises above designated size (take the logarithm) }\end{array}$ \\
\hline & $\begin{array}{l}\text { Sulfur dioxide emission intensity / } \\
\text { ton / million US\$ }\end{array}$ & $\mathrm{LNemso}_{\mathrm{t}}$ & $\begin{array}{l}\text { Industrial sulfur dioxide emission amount / values added of } \\
\text { industrial enterprises above designated size (take the logarithm) }\end{array}$ \\
\hline & $\begin{array}{l}\text { Nitrogen oxide emission intensity / } \\
\text { ton / million US\$ }\end{array}$ & LNemnox $_{t}$ & $\begin{array}{l}\text { Industrial nitrogen oxide emission amount / values added of } \\
\text { industrial enterprises above designated size (take the logarithm) }\end{array}$ \\
\hline & $\begin{array}{l}\text { Ammonia nitrogen emission } \\
\text { efficiency / thousand US\$ / ton }\end{array}$ & LNemand $_{t}$ & $\begin{array}{l}\text { values added of industrial enterprises above designated size / } \\
\text { industrial ammonia nitrogen emission amount (take the logarithm) }\end{array}$ \\
\hline & $\begin{array}{l}\text { Smoke and dust emission intensity } \\
\text { / ton / million US\$ }\end{array}$ & LNemyan $_{t}$ & $\begin{array}{c}\text { Smoke and dust emission amount / values added of industrial } \\
\text { enterprises above designated size (take the logarithm) }\end{array}$ \\
\hline & $\begin{array}{l}\text { COD emission intensity / ton } \\
\text { / million US\$ }\end{array}$ & LNemcod $_{t}$ & $\begin{array}{c}\text { COD emission amount / values added of industrial enterprises } \\
\text { above designated size (take the logarithm) }\end{array}$ \\
\hline \multirow{6}{*}{$\begin{array}{l}\text { Explanatory } \\
\text { variable }\end{array}$} & $\begin{array}{c}\text { Fiscal expenditure on energy } \\
\text { conservation and environmental } \\
\text { protection/ thousand US\$ }\end{array}$ & $\mathrm{LNec}_{\mathrm{t}}$ & $\begin{array}{l}\text { Local government budgetary expenditure on energy conservation } \\
\text { and environmental protection (take the logarithm) }\end{array}$ \\
\hline & $\mathrm{R} \& \mathrm{D} /$ thousand US\$ & $\operatorname{LNrd}_{t}$ & $\begin{array}{l}\text { Expenditures of Industrial Enterprises above Designated Size on } \\
\text { R\&D (take the logarithm) }\end{array}$ \\
\hline & Fiscal decentralization $/ \%$ & $\operatorname{LNcf}_{t}$ & $\begin{array}{c}\text { Local government budgetary expenditure / local government } \\
\text { budgetary revenue (take the logarithm) }\end{array}$ \\
\hline & $\begin{array}{l}\text { Proportion of state-owned enterpris- } \\
\text { es in industrial enterprises } / \%\end{array}$ & $\operatorname{LNgp}_{t}$ & $\begin{array}{l}\text { Proportion of state-owned enterprises in the values added of } \\
\text { industrial enterprises above designated size (take the logarithm) }\end{array}$ \\
\hline & $\begin{array}{l}\text { Proportion of heavy industry in } \\
\text { industrial enterprises } / \%\end{array}$ & $\mathrm{LNhr}_{\mathrm{t}}$ & $\begin{array}{l}\text { Proportion of heavy industry in the values added of industrial } \\
\text { enterprises above designated size (take the logarithm) }\end{array}$ \\
\hline & $\begin{array}{l}\text { Fixed assets per unit of industrial } \\
\text { value added / thousand US\$ }\end{array}$ & LNinin $_{t}$ & $\begin{array}{c}\text { Value added of industrial enterprises above designated size / total } \\
\text { fixed assets (take the logarithm) }\end{array}$ \\
\hline \multirow{3}{*}{$\begin{array}{l}\text { Instrumental } \\
\text { variable }\end{array}$} & Fiscal revenue / million US\$ & LNcshou $_{t}$ & Local government budgetary revenue (take the logarithm) \\
\hline & $\begin{array}{l}\text { Total profits and taxes of industrial } \\
\text { enterprises / million US\$ }\end{array}$ & LNlishui $_{t}$ & $\begin{array}{l}\text { Total profits and taxes of industrial enterprises above designated } \\
\text { size (take the logarithm) }\end{array}$ \\
\hline & $\begin{array}{c}\text { Industrial enterprises' ratio of Profits } \\
\text { and taxes to total assets } / \%\end{array}$ & LNlshra $_{t}$ & $\begin{array}{l}\text { Total profits and taxes / total assets of industrial enterprises above } \\
\text { designated size (take the logarithm) }\end{array}$ \\
\hline
\end{tabular}


For this study, seven basic models were designed.

$$
\begin{aligned}
& \text { LNenergy }_{i, t}=\beta_{11}+\beta_{12} L N e c_{i, t}+\beta_{13} L N r d_{i, t}+\beta_{14} L N c f_{i, t} \\
& +\beta_{15} L N h r_{i, t}+\beta_{16} L N g p_{i, t}+\beta_{17} L_{N i n i n} i, t+u_{i, t}
\end{aligned}
$$

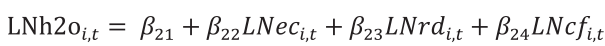

$$
\begin{aligned}
& +\beta_{25} L N h r_{i, t}+\beta_{26} L N g p_{i, t}+\beta_{27} L_{N i n i n}, t+u_{i, t} \\
& \text { LNemso }_{i, t}=\beta_{31}+\beta_{32} L N e c_{i, t}+\beta_{33} L N r d_{i, t}+\beta_{34} L N c f_{i, t} \\
& +\beta_{35} L N h r_{i, t}+\beta_{36} L N g p_{i, t}+\beta_{37} L_{N i n i n}, t+u_{i, t} \\
& \text { LNemnox }_{i, t}=\beta_{41}+\beta_{42} L N e c_{i, t}+\beta_{43} L N r d_{i, t}+\beta_{44} L N c f_{i, t} \\
& +\beta_{45} L N h r_{i, t}+\beta_{46} L N g p_{i, t}+\beta_{47} \operatorname{LNinin}_{i, t}+u_{i, t} \\
& \operatorname{LNemand}_{i, t}=\beta_{51}+\beta_{52} L N e c_{i, t}+\beta_{53} L N r d_{i, t}+\beta_{54} L N c f_{i, t} \\
& +\beta_{55} L N h r_{i, t}+\beta_{56} L N g p_{i, t}+\beta_{57} L_{N i n i n}, t+u_{i, t} \\
& \text { LNemyan }_{i, t}=\beta_{61}+\beta_{62} L N e c_{i, t}+\beta_{63} L N r d_{i, t}+\beta_{64} L N c f_{i, t} \\
& +\beta_{65} L N h r_{i, t}+\beta_{66} L N g p_{i, t}+\beta_{67} L \text { Ninin }_{i, t}+u_{i, t} \\
& \operatorname{LNemcod}_{i, t}=\beta_{71}+\beta_{72} L N e c_{i, t}+\beta_{73} L N r d_{i, t}+\beta_{74} L N c f_{i, t} \\
& +\beta_{75} L N h r_{i, t}+\beta_{76} L N g p_{i, t}+\beta_{77} L_{N i n i n}{ }_{i, t}+u_{i, t}
\end{aligned}
$$

Data Processing and Model Selection

\section{Linear Correlation Analysis and Multicollinearity Diagnosis}

Enterprises' activities related to energy conservation and pollutant emission reduction generally involve investment activities such as production line renovation and equipment upgrading, and the life cycle usually lasts for a period of time, which also means that government FEECEP has hysteresis effect. At the same time, both government FEECEP and corporate R\&D investment have the effects of energy conservation and pollutant emission reduction, so that there is the possibility of multiple collinearity between the two variables. Based on these two points, it is necessary to do a simple linear correlation analysis of the data before data processing and model estimation. The results of the analysis are shown in Table 7. Among them, $t-1, t-2$, and $t-3$ represent the data of related indicators lag one, two and three periods respectively.

In terms of the correlation coefficient, there is a high correlation between energy consumption intensity (energy $_{t}$ ) in the $t$ period and enterprise's $\mathrm{R} \& \mathrm{D}$ investment $\left(\mathrm{rd}_{\mathrm{t}}\right)$ in the $t$ period, or its data of lag one, lag two, lag three periods. It is the same to the correlation between energy consumption intensity and government FEECEP. At the same time, the correlation between the two core explanatory variables and their three-period lag values is also very high. The correlation analysis between the other five explained variables and these two core explanatory variables also shows the same characteristics. Due to the limitation of the length of the paper, the relevant analysis results are omitted.

To avoid multiple collinearities affecting the validity of the estimated model, the three-period lag values of the two core explanatory variables are incorporated into the model estimation, and the principal component analysis method is adopted to deal with dimension reduction. Together with other non-core explanatory variables, the new generated variables, which replace the two original core explanatory variables, are employed to make a regression analysis with explained variables. Due to the inclusion of three periods of lag data, degrees of freedom of the regression model will be reduced by three years. The results of principal component analysis are shown in Table 8 and Table 9.

Table 8. Initial eigenvalues of principal component analysis and the total variance of explained.

\begin{tabular}{|c|c|c|c|}
\hline Component & Eigenvalue & Difference & Proportion \\
\hline Comp1 & 6.04049 & 5.33398 & 0.7551 \\
\hline Comp2 & 0.706509 & 0.226482 & 0.0883 \\
\hline Comp3 & 0.480027 & 0.0132414 & 0.0600 \\
\hline
\end{tabular}

Table 7. Correlation Analysis of Fiscal expenditure on Energy Saving and Environmental Protection, Enterprise R \& D Investment, and their lag data of 17 prefecture-cities in Shandong Province from 2010 to 2017.

\begin{tabular}{|c|c|c|c|c|c|c|c|c|c|}
\hline & $\mathrm{ec}_{\mathrm{t}}$ & $\mathrm{Ec}_{\mathrm{t}-1}$ & $\mathrm{Ec}_{\mathrm{t}-2}$ & $\mathrm{Ec}_{\mathrm{t}-3}$ & $\mathrm{rd}_{\mathrm{t}}$ & $\mathrm{rd}_{\mathrm{t}-1}$ & $\mathrm{rd}_{\mathrm{t}-2}$ & $\mathrm{rd}_{\mathrm{t}-3}$ & $\mathrm{energy}_{\mathrm{t}}$ \\
\hline $\mathrm{ec}_{\mathrm{t}}$ & 1 & & & & & & & \\
\hline $\mathrm{ec}_{\mathrm{t}-1}$ & 0.656 & 1 & & & & & & \\
\hline $\mathrm{ec}_{\mathrm{t}-2}$ & 0.5207 & 0.6276 & 1 & & & & & \\
\hline $\mathrm{ec}_{\mathrm{t}-3}$ & 0.5811 & 0.4855 & 0.5918 & 1 & & & & & \\
\hline $\mathrm{rd}_{\mathrm{t}}$ & 0.6408 & 0.6464 & 0.6628 & 0.6976 & 1 & & & & \\
\hline $\mathrm{rd}_{\mathrm{t}-1}$ & 0.6333 & 0.6328 & 0.6535 & 0.7045 & 0.9945 & 1 & & & \\
\hline $\mathrm{rd}_{\mathrm{t}-2}$ & 0.6317 & 0.6337 & 0.6478 & 0.7087 & 0.9844 & 0.994 & 1 & & \\
\hline $\mathrm{rd}_{\mathrm{t}-3}$ & 0.6223 & 0.6323 & 0.6473 & 0.702 & 0.9684 & 0.9819 & 0.9926 & 1 & \\
\hline $\mathrm{energy}_{\mathrm{t}}$ & 0.4471 & 0.4274 & 0.4149 & 0.3968 & 0.5359 & 0.5179 & 0.4983 & 0.4781 & 1 \\
\hline
\end{tabular}


Table 9. Conversion coefficients between core explanatory variables and newly generated variables.

\begin{tabular}{|c|c|c|c|c|c|c|c|c|}
\hline Component & $\mathrm{ec}_{\mathrm{t}}$ & $\mathrm{ec}_{\mathrm{t}-1}$ & $\mathrm{ec}_{\mathrm{t}-2}$ & $\mathrm{ec}_{\mathrm{t}-3}$ & $\mathrm{rd}_{\mathrm{t}}$ & $\mathrm{rd}_{\mathrm{t}-1}$ & $\mathrm{rd}_{\mathrm{t}-2}$ & $\mathrm{rd}_{\mathrm{t}-3}$ \\
\hline Comp1 & 0.3054 & 0.307 & 0.3103 & 0.3198 & 0.3922 & 0.3926 & 0.3925 & 0.3897 \\
\hline Comp2 & 0.4994 & 0.5933 & 0.3247 & -0.0405 & -0.2453 & -0.276 & -0.2799 & -0.2772 \\
\hline Comp3 & -0.4528 & -0.1854 & 0.7337 & 0.4205 & -0.1061 & -0.1071 & -0.1111 & -0.1018 \\
\hline
\end{tabular}

Table 10. Results of stationary test.

\begin{tabular}{|c|c|c|c|c|}
\hline Symbol & Indicator & Levin, Lin \& Chut* & ADF-Fisher Chi-square & PP-Fisher Chi-square \\
\hline \multirow{2}{*}{ LNenergyt } & Statistic & -28.0508 & 247.234 & 301.415 \\
\hline & Prob. & 0.0000 & 0.0000 & 0.0000 \\
\hline \multirow{2}{*}{$\mathrm{LNh} 2 \mathrm{o}_{\mathrm{t}}$} & Statistic & -8.2835 & 83.4853 & 113.446 \\
\hline & Prob. & 0.0000 & 0.0000 & 0.0000 \\
\hline \multirow{2}{*}{ LNemso $_{t}$} & Statistic & -8.97889 & 113.787 & 130.628 \\
\hline & Prob. & 0.0000 & 0.0000 & 0.0000 \\
\hline \multirow{2}{*}{ LNemnox $_{t}$} & Statistic & -6.12183 & 51.9919 & 54.6325 \\
\hline & Prob. & 0.0000 & 0.0000 & 0.0000 \\
\hline \multirow{2}{*}{ LNemand $_{t}$} & Statistic & -7.66935 & 56.1867 & 84.7980 \\
\hline & Prob. & 0.0000 & 0.0097 & 0.0000 \\
\hline \multirow{2}{*}{ LNemyan $_{t}$} & Statistic & -6.12967 & 79.6689 & 100.748 \\
\hline & Prob. & 0.0000 & 0.0000 & 0.0000 \\
\hline \multirow{2}{*}{ LNemcod $_{t}$} & Statistic & -9.65558 & 128.700 & 196.035 \\
\hline & Prob. & 0.0000 & 0.0000 & 0.0000 \\
\hline \multirow{2}{*}{ LNComp $1_{t}$} & Statistic & -17.9589 & 156.6610 & 262.198 \\
\hline & Prob. & 0.0000 & 0.0000 & 0.0000 \\
\hline \multirow{2}{*}{ LNComp $2_{t}$} & Statistic & -13.2138 & 140.771 & 200.395 \\
\hline & Prob. & 0.0000 & 0.0000 & 0.0000 \\
\hline \multirow{2}{*}{ LNComp $3_{t}$} & Statistic & -101.889 & 167.935 & 164.337 \\
\hline & Prob. & 0.0000 & 0.0000 & 0.0000 \\
\hline \multirow{2}{*}{$\mathrm{LNcf}_{\mathrm{t}}$} & Statistic & -10.9682 & 88.5587 & 106.918 \\
\hline & Prob. & 0.0000 & 0.0000 & 0.0000 \\
\hline \multirow{2}{*}{$\mathrm{LNgp}_{\mathrm{t}}$} & Statistic & -4.9903 & 62.9946 & 63.1817 \\
\hline & Prob. & 0.0000 & 0.0018 & 0.0017 \\
\hline \multirow{2}{*}{$\mathrm{LNhr}_{\mathrm{t}}$} & Statistic & -6.5804 & 62.3916 & 71.2040 \\
\hline & Prob. & 0.0000 & 0.0021 & 0.0002 \\
\hline \multirow{2}{*}{ LNinin $_{t}$} & Statistic & -22.4331 & 46.1548 & 60.1850 \\
\hline & Prob. & 0.0000 & 0.0798 & 0.0037 \\
\hline \multirow{2}{*}{ LNcshou $_{t}$} & Statistic & -18.8648 & 117.619 & 193.864 \\
\hline & Prob. & 0.0000 & 0.0000 & 0.0000 \\
\hline \multirow{2}{*}{ LNlishui $_{t}$} & Statistic & -9.8317 & 57.4219 & 70.5898 \\
\hline & Prob. & 0.0000 & 0.0073 & 0.0002 \\
\hline \multirow{2}{*}{ LNlshra $_{t}$} & Statistic & -6.87651 & 65.8163 & 68.7353 \\
\hline & Prob. & 0.0000 & 0.0009 & 0.0004 \\
\hline
\end{tabular}


The expressions of the first three principal components with relatively large eigenvalues are:

$$
\begin{aligned}
& \text { Compl }=0.3054 \mathrm{ec}_{\mathrm{t}}+0.307 \mathrm{ec}_{\mathrm{t}-1}+0.3103 \mathrm{ec}_{\mathrm{t}-2} \\
& +0.3198 \mathrm{ec}_{\mathrm{t}-3}+0.3922 \mathrm{rd}_{\mathrm{t}}+0.3926 \mathrm{rd}_{\mathrm{t}-1} \\
& +0.3925 \mathrm{rd}_{\mathrm{t}-2}+0.3897 \mathrm{rd}_{\mathrm{t}-3} \\
& \text { Comp2 }=0.4994 \mathrm{ec}_{\mathrm{t}}+0.5933 \mathrm{ec}_{\mathrm{t}-1} \\
& +0.3247 \mathrm{ec}_{\mathrm{t}-2}-0.0405 \mathrm{ec}_{\mathrm{t}-3}-0.2453 \mathrm{rd}_{\mathrm{t}} \\
& -0.276 \mathrm{rd}_{\mathrm{t}-1}-0.2799 \mathrm{rd}_{\mathrm{t}-2}-0.2772 \mathrm{rd}_{\mathrm{t}-3} \\
& \text { Comp3 }=-0.4528 \mathrm{ec}_{\mathrm{t}}-0.1854 \mathrm{ec}_{\mathrm{t}-1} \\
& +0.7337 \mathrm{ec}_{\mathrm{t}-2}+0.4205 \mathrm{ec}_{\mathrm{t}-3}-0.1061 \mathrm{rd}_{\mathrm{t}} \\
& -0.1071 \mathrm{rd}_{\mathrm{t}-1}-0.1111 \mathrm{rd}_{\mathrm{t}-2}-0.1018 \mathrm{rd}_{\mathrm{t}-3}
\end{aligned}
$$

\section{Stationarity Test}

The prerequisite for making a regression analysis is that the panel series data must undergo the stationary test. In this study, the methods of LLC, ADF, and PP are used to test the stationarity of panel data. The test results (Table 10) show that each sequence of panel data does not contain a unit root and passes the stationary test.

\section{Model Selection}

Model selection is the basis of making a regression analysis with panel data. In order to increase the comparison, the model parameters were also estimated by mixed regression and inter-group regression methods. Limited by the length of this paper, this paper only takes the basic Model (2) as an example to estimate the quantitative relationship between energy consumption intensity per unit of industrial value added and government fiscal expenditure for energy conservation and environmental protection, as well as other explanatory variables. The estimated results are shown in Table 11, which shows that the parameters estimated by the fixed effects model differ far from those obtained by other estimation methods. In this study, stata14 software is used to analyze the panel data.
At the same time, due to the large difference between the cluster robust standard error and the general standard error, the traditional Hausmann test is not applicable, and the problem can be solved by auxiliary regression according to Formula (9) and Formula (10) [18].

$$
\begin{gathered}
y_{i t}-\hat{\theta} \bar{y}_{l}=\left(\boldsymbol{x}_{i t}-\hat{\theta} \overline{\boldsymbol{x}}_{\boldsymbol{\imath}}\right)^{\prime} \boldsymbol{\beta}+(1-\hat{\theta}) z_{i}{ }^{\prime} \boldsymbol{\delta} \\
+\left(\boldsymbol{x}_{i t}-\overline{\boldsymbol{x}}_{\imath}\right)^{\prime} \boldsymbol{\gamma}+\left[(1-\hat{\theta}) u_{i}+\left(\varepsilon_{i t}-\hat{\theta} \bar{\varepsilon}_{\imath}\right)\right] \\
y_{i t}=\boldsymbol{x}_{i t}{ }^{\prime} \beta+\boldsymbol{z}_{i}{ }^{\prime} \delta+u_{i}+\varepsilon_{i t}
\end{gathered}
$$

$y_{i t}$ and $x_{i t}$ are the explained variables and explanatory variables in the $t$ period of city $i ; u_{i}$ and $x_{i t}$ are both error term or disturbance; $z_{i}$ is an individual characteristic that does not change over time; $\bar{y}, \bar{x}_{l}$, and $\bar{\varepsilon}$, are the explained variable, explanatory variable and error term, which are obtained by averaging both sides of the individual effects model over time for city $i ; \hat{\theta}, \beta, \delta$, and $\gamma$ are the parameters to be estimated.

The above auxiliary regression can be performed by executing a Stata unofficial command named xtoverid. The auxiliary regression shows that the value of $\mathrm{x}^{2}$ (7) statistic is 32.322 and the $P$ value is 0.0000 . The F distribution is equivalent to the $\mathrm{x}^{2}$ distribution when the sample is big enough, and a $\mathrm{P}$ value of 0 means that the null hypothesis is strongly rejected, that is, random effects are rejected. Other $x^{2}(7)$ statistics and $\mathrm{P}$ values can be obtained by performing auxiliary regression on basic models (3), (4), (5), (6), (7) and (8), as shown in Table 12. It is concluded that all seven basic models in this study are more suitable for estimation by the fixed effects model.

\section{Accounting for Pollution Reduction Effects of FEECEP}

There are two new variables generated by the principal component method: LNcomp1 and LNcomp2 in the model explanatory variables. According to the method described in the previous section, the change

Table 11. Model parameters estimated by different methods.

\begin{tabular}{|c|c|c|c|c|}
\hline Variable & OLS & FE_robust & RE & BE \\
\hline LNcomp1 & -0.422488 & -0.266418 & -0.288196 & -0.425284 \\
\hline LNcomp2 & -0.009588 & -0.002754 & -0.003281 & -0.01263175 \\
\hline LNcomp3 & -0.001308 & -0.001537 & -0.001171 & -0.01089219 \\
\hline LNinin & 0.023159 & -0.148884 & -0.124524 & 0.16193432 \\
\hline LNgp & -0.044550 & -0.003387 & -0.005566 & -0.17813355 \\
\hline LNcf & 0.393807 & 0.253232 & 0.230400 & 0.34625731 \\
\hline LNhr & -0.423849 & -0.162000 & -0.247600 & -0.433874 \\
\hline cons & 14.520224 & 13.658305 & 14.127879 & 13.692413 \\
\hline
\end{tabular}

Annotation: OLS is pooled regression; FE_robust is a fixed effects regression; robust indicates that adopt cluster-robust standard error; $\mathrm{RE}$ is random effects regression; $\mathrm{BE}$ is between estimator. 
Table 12. Test results of model form selection.

\begin{tabular}{|c|c|c|c|c|c|c|c|}
\hline Index & LNenergy & LNh2o & LNemso & LNemnox & LNemand & LNemyan & LNemcod \\
\hline Chi-sq(7) & 32.322 & 117.448 & 13.139 & 21.08 & 22.683 & 46.454 & 15.580 \\
\hline P & 0.0000 & 0.0000 & 0.0688 & 0.0018 & 0.0019 & 0.0000 & 0.0292 \\
\hline
\end{tabular}

Annotation: the first line uses the symbol of the explained variable to represent the basic type of the model.

rates of annual pollutant emission intensity or resource consumption intensity caused by the variation of these two new variables can be calculated, and then the pollutant emission reduction and resource saving caused by it can be calculated. In order to obtain the share caused by government FEECEP, it needs to be further separated from the effects of energy conservation and pollutant emission reduction of newly generated variables. The separation method can be calculated according to equations (11) and (12).

$$
\begin{gathered}
\operatorname{propec}_{i, j, l}=\frac{\alpha_{l} e c_{l}-\alpha_{l-1} e c_{l-1}}{\operatorname{comp} p_{s, t}-\operatorname{comp} p_{s, t-1}} \\
\operatorname{comp}_{s, t}=\sum_{l=0}^{-3}\left(\alpha_{l} e c_{l}+\beta_{l} r d_{l}\right)
\end{gathered}
$$

propec $_{i, j, l}$ is the share of FEECEP in the emission reduction of $j$ pollutant in city $i$ in the $t$ period; $l$ can take four values, $0,-1,-2$, and -3 , representing the current period and the lag one period, two periods, and three periods. The negative sign indicates the number of periods lagging relative to period $t . \alpha_{1}$ and $\beta$ are the conversion coefficients between the new variable $s$ and two core explanatory variables, that is, government FEECEP and R \& D investment of industrial enterprises. Their values are shown in Table 8. comp $p_{s, t}$ is the value of the new variable $s$ in the $t$ period.

Following the principle of causality, considering the lag effect of three periods, the pollutants reduction caused by government FEECEP in a certain year includes the contribution of this kind of fiscal expenditure in the previous three periods. When calculating pollutant reduction or energy saving caused by the government FEECEP in the three years from 2010 to 2012, the share before 2009 is removed in order to reduce the calculation complexity.

The calculation of pollutant emission reduction or resource saving caused by this expenditure needs to take into account its lag effect, which can be calculated according to Formula (13).

$$
Q P e c_{i, j, t}=\sum_{m=0}^{3}\left(Q P \operatorname{comp}_{i, j, t+m} \times \operatorname{propec}_{i, j, t+m}\right)
$$

$Q P e c_{i, j, t}$ is the $j$ pollutant emission reduction caused by the government FEECEP during the $t$ period; QPcomp $_{i, j, t+m}$ is the $j$ pollutant emission reduction caused by the new variables in the $t+m$ period; $m$ can take four values, $0,1,2$ and 3 , representing the next four years from the beginning of the $t$ period.

\section{Analysis on the Effect of Resource Saving and Pollutant Emission Reduction Caused by Government FEECEP}

Still taking the reduction of sulfur dioxide emissions as an example, the annual amount of pollutant emission reduction $\left(Q s o_{i, t}\right)$ is also easy to calculate, as shown in Formula (14).

$$
Q s o_{i, t}=\operatorname{ingdp}_{i, t} \times\left(\frac{\text { qemso }_{i, t-1}}{\operatorname{ingdp}_{i, t-1}}-\frac{q e m s o_{i, t}}{\left.\operatorname{ingdp_{i,t}}\right)}\right.
$$

$Q s O_{i, t}$ is the amount of industrial sulfur dioxide emission reduction in the $t$-period of city $i$. qemso $o_{i, t}$ is the amount of industrial sulfur dioxide emission in the $t$-period of city $i$. ingd $p_{i, t}$ is the industrial added value in the $t$-period of city $i$.

The key step in calculating the emission reduction caused by government FEECEP is how to separate this kind of share from the annual total amount of pollutant emission reduction according to Model (4). The calculation method of $\beta_{22}$ can be inferred from formula (15)

$$
\operatorname{RESR}_{i, t}=\left(1+e r_{i, t}\right)^{\beta_{22}}-1
$$

Here, $\operatorname{RESR}_{i, t}$ is the response coefficient of the explained variable to the change of the explanatory variable, which means the change rate of $\mathrm{emso}_{i, t}$ caused by the change of $e r_{i, t}$ under the premise that other conditions remain unchanged. If the factors that play a leading role in the change of emso $_{i, t}$ can be determined, and the rate of change in $\mathrm{emso}_{i, t}$ caused by the dominant factor is much higher than that caused by the non-dominant factor, it is still of practical reference value to deduce the role of the dominant factor played in the change of the explained variable by using the response coefficient of the explained variable to the change of the explanatory variable $\left(R E S R_{i, t}\right)$.

Assuming that there are $m$ core explanatory variables and $n$ non-core explanatory variables, the sum of the change rate of emso ${ }_{i, t}$ caused by these two kind of factors can be calculated by Formulas (16) and (17).

$$
D_{S R_{i, t}}=\sum_{d=1}^{m} R E S R_{i, d, t}
$$




$$
O S R_{i, t}=\sum_{o=1}^{n} R E S R_{i, o, t}
$$

$D S R_{i, t}$ is the sum of the change rate of emso ${ }_{i, t}$ caused by the core explanatory variables in the $t$ period of city $i ; O S R_{i, t}$ is the sum of the change rate of emso ${ }_{i, t}$ caused by non-core explanatory variables in the $t$ period of city $i$. Since both of these are partial effects calculated under the same assumption that other conditions remain unchanged, they must be revised when determining their real effects.

Let $T S R_{i, t}$ be set as the total change rate of emso $_{i, t}$ in the t period of city $i$. There is an issue of goodnessof-fit in the econometric model, which manifests to what extent the fluctuation amplitude of the explained variable can be explained by the estimated model [8]. When calculating the share of an explanatory variable in the total change rate of the explained variable, the value of $T S R_{i, t}$ should be multiplied by the value of the determinable coefficient $\mathrm{R}^{2}$, and the corrected index here are renamed $R T S R_{i, t}$. When the annual change values of a non-core explanatory variable in some periods is very large, the coefficients estimated through regression analysis would contorted greatly, making the roles of core explanatory variables inferred from econometric model far away from the real situation. In order to avoid the above situation, a flexible calculation method can be considered, as shown in Formula (18).

$$
R D S R_{i, t}=D S R_{i, t}+O S R_{i, t} \times \frac{1}{l} \sum_{j=1}^{l} \sum_{t=2011}^{t=2017} \frac{\left(R T S R_{j, t}-O S R_{j, t}-D S R_{j, t}\right)}{O S R_{j, t}}
$$

$R D S R_{i, t}$ is the revised sum of the change rate of emso $_{i, t}$ caused by the core explanatory variables in the $t$ period of city $i$, where the panel data of Shandong prefecture-level cities are taken as analysis samples, and $l$ is equal to 17 . The change of the non-core explanatory variable will counteract or increase the effect of the core explanatory variable. The symbol AVROD is used to represent the sector of $\frac{1}{l} \sum_{j=1}^{l} \sum_{t=2011}^{t=2017} \frac{\left(R T S R_{j, t}-O S R_{j, t}-D S R_{j, t}\right)}{O S R_{j, t}}$ in the Formula (18). If there is an abnormally high value of $\frac{\left(R T S R_{j, t}-O S R_{j, t}-D S R_{j, t}\right)}{O S R_{j, t}}$, it will greatly increase its influence on the value of AVROD. In order to prevent a small number of extremes from excessively affecting the size of the value of AVROD, we deleted the top $10 \%$ of the largest value of $\frac{\left(R T S R_{j, t}-O S R_{j, t}-D S R_{j, t}\right)}{O S R_{j, t}}$ from the sample data when calculating the value of AVROD.

If $R D S R_{i, t}$ is set to be equal to $\alpha D S R_{i, t}$, the effect value of a single core explanatory variable's change can be calculated by Formula (19).

$$
\operatorname{RDSR}_{i, d, t}=\alpha R E S R_{i, d, t}
$$

$R D S R_{i, d, t}$ is the change rate of the explained variable caused by the change of the $d$ core explanatory variable in $t$ period in city $i ; R D S R_{i, d, t} \mathrm{~s}$ the response coefficient of the explained variable of city $i$ to the change of the $d$ explanatory variable in $t$ period, as shown in Formula (15).

\section{The Calculation Method of the Total Amount of Resource Saving and Emission Reduction Caused by the Government FEECEP}

The growth rate of this expenditure in each year can be calculated when the time series data of government FEECEP are obtained. The growth rate is multiplied by $R D S R_{i, d, t}$, which is the change rate of the explained variable caused by the change of the $d$ core explanatory variable in city $i$ (the $d$ core explanatory variable here refers to the government FEECEP, the calculation process is shown in Formula (19)), we can obtain the change rate of pollutant emission intensity, and the amount of pollutant emission reduction caused by this expenditure in the corresponding year can then be calculated. Taking the calculation of energy conservation amount as an example, the calculation process is shown in Formula (20).

$$
Q E_{i, t}=\operatorname{energy}_{i, t-1} \times R D S R_{i, t} \times e c r_{t} \times \text { indus }_{t}
$$

$Q E_{i, t}$ is the amount of energy saving in the $t$ period of city $i$; energy $y_{i, t-1}$ is the energy consumption intensity in the $t$ period of city $i$; ecr $r_{i, t}$ is the change rate of government energy saving and environmental protection expenditure in the $t$ period of city $i$. The calculation process can be seen in Formula (21). indus ${ }_{i, t}$ is the industrial added value in the $t$ period of city $i$.

$$
e c r_{i, t}=\frac{e c_{i, t}-e c_{i, t-1}}{e c_{i, t-1}}
$$

$e c_{i, t}$ is the amount of government FEECEP in the $t$ period of city $i$.

Positive externality, such as the implementation of cleaner production or the development of the circular economy, will, like a fixed asset investment, play a stable role in a period of time once an operating mechanism or mode of the enterprise is formed, until it enters another life cycle. Therefore, when estimating the effect of resource saving and emission reduction caused by government FEECEP, It is necessary to set a period of time during which the effects caused by government FEECEP continue to play a role.

With reference to the national regulations on the depreciation life of industrial fixed assets, this study considers the effect caused by FEECEP over three periods of time: 10 years, 15 years, and 20 years in order to investigate their impact on performance evaluation. That is, enterprises' activities and its relative facilities with positive externality caused by this expenditure can operate continuously for 10 years, 15 years, and 20 years. During this period, in principle, there is no need for additional government investment, and the effects caused by FEECEP will continue to play a role. Taking the energy-saving effect that would last 
for 10 years as an example, the government FEECEP during the $t$ period has led to a decrease in the energy consumption intensity, which is not directly caused by governmental behavior, but is indirectly realized through guiding enterprises to carry out economic activities with positive externalities such as the renovation of production equipment, the development of circular economy or cleaner production. During the $t$ period, the amount of energy saving generated by this expenditure will be the cumulative amount of 10 years, which is calculated by Formula (22).

$T Q E_{i, t}=\left(\right.$ energy $\left._{i, t-1} \times R D S R_{i, t} \times e c r_{i, t}\right) \times 10 \times$ indus $_{i, t}$

$T Q E_{i, t}$ is the total amount of energy saving caused by the government FEECEP during the $t$ period of city $i$. Calculating the total amount of energy saving based on formula (24) means that the city's industrial production scale remains unchanged during this period. If the energy-saving effect of government FEECEP remains unchanged in the situation that the industrial scale expanded continually, then $T Q E_{i, t}$ should be calculated by Formula (23).

$$
T Q E_{i, t}=\left(\operatorname{energy}_{i, t-1} \times R D S R_{i, t} \times e c r_{i, t}\right) \times\left(\sum_{j=0}^{9} \text { indus }_{i, t+j}\right)
$$

$\Sigma^{9}{ }_{j=0}$ ind $_{\text {ins }}$ itt+j is the sum of the industrial added value of the city $i$ in 10 years, and $j=0,1,2, \ldots, 9$, which represents the $t$ period and the following 9 years.

In order to pass the stationarity test of time series data in regression analysis, the explained variable of Model (6), which is different from other models, adopts the index of ammonia nitrogen emission efficiency, which can be seen in Table 5. The econometric model can be used to calculate the change rate of ammonia nitrogen emission efficiency caused by the change of annual FEECEP. For the sake of convenience, it is necessary to convert the ammonia nitrogen emission efficiency into ammonia nitrogen emission intensity (ammonia nitrogen emission per unit of industrial value added) when calculating the amount of industrial ammonia nitrogen emission reduction caused by the improvement of ammonia nitrogen emission efficiency. Because the ammonia nitrogen emission efficiency is the reciprocal of the ammonia nitrogen emission intensity, the latter can be calculated according to the former, shown as Formula (24). For the sake of shortening the length of the article, the derivation process is omitted.

$$
\Delta \mathrm{INand} d_{i, t}=\frac{1}{\Delta E \text { Fand }_{i, t}+1}-1
$$

$\triangle$ EFand $_{i, t}$ is the change rate of ammonia nitrogen emission efficiency caused by government FEECEP in the $t$ period of city $i$, and $\triangle I N a n d_{i, t}$ indicates the change rate of ammonia nitrogen emission intensity caused by government FEECEP in the $t$ period of city $i$.
The calculation methods are shown in Formulas (25) and (26). $\triangle E F$ and $_{i, t}$ and $\Delta$ INand $_{i, t}$ indicate the ammonia nitrogen emission efficiency and ammonia nitrogen emission intensity of the corresponding cities and years.

$$
\begin{aligned}
\Delta \text { EFand }_{i, t} & =\frac{\text { EFand }_{i, t}-\text { EFand }_{i, t-1}}{\text { EFand }_{i, t-1}} \\
\Delta \mathrm{INand} & \\
\text { I }_{i, t} & =\frac{\mathrm{INand}_{i, t}-\mathrm{INand}_{i, t-1}}{\mathrm{INand}}{ }_{i, t-1}
\end{aligned}
$$

\section{Calculation of Environmental Value per Unit Pollutant Emission Reduction}

This study takes the investment profit margin into account when determining the environmental value of pollutant emission reduction and resource saving. The calculation method is shown in Formula (27).

$$
P_{i, t, j}=\frac{b f_{i, t, j} \times\left(1+r_{i, t}\right)}{Q P_{i, t, j}}
$$

$P_{i, t, j}$ is the environmental value of the $j$ pollutant emission reduction in the $\mathrm{t}$ period of city $\mathrm{i}$ (unit price); $b f_{i, t, j}$ is the operating cost of the $j$ pollutant disposal facility in the $t$ period of city $i ; r_{i, t}$ is the industrial enterprises' ratio of profits to cost in the $t$ period of city $i ; Q P_{i, t, j}$ is the amount of the $j$ pollutant removed in the city $i$ during the $t$ period.

For the sake of convenience, taking the proportion of the amount of a pollutant removed in each year to the total amount of the pollutant removed during the whole studied period as a weight, calculate each pollutant's weighted average environmental value in each city respectively, which is used as the basic parameter to calculate the total environmental value of resource saving and pollutant emission reduction caused by FEECEP in every prefecture-level city. The calculation method is shown in Formula (28).

$$
P_{i, j}=\sum_{t=T_{1}}^{t=T_{2}}\left(\frac{Q P_{i, t, j} \times P_{i, t, j}}{\sum_{t=T_{1}}^{t=T_{2}} Q P_{i, t, j}}\right)
$$

The operating cost of industrial waste gas disposal facilities in provincial statistical data includes the sub-data of operating costs of installations for desulfurization, denitration, and dedusting, and the data of removal amount of every pollutant are also available, so it is not difficult to obtain the average disposal cost of each year for every pollutant. However, the operating cost of industrial waste water disposal facilities in provincial statistical data does not includes the subdata of operating costs of installations for removals of chemical oxygen demand and ammonia nitrogen, which makes it more difficult to obtain the costs of this two pollutants emission reduction. The COD and ammonia nitrogen removal cost parameters of sewage treatment plants exist in the relevant literature [19]. Considering the regional differences, we take the proportion (1:7) 
between removal costs of COD and ammonia nitrogen in this literature as a key parameter to calculate the environmental values of COD and ammonia nitrogen emission reduction in Shandong province and its prefecture-level cities.

Taking the proportion of the amount of a pollutant removed in each prefecture-level city to the total amount of the pollutant removed in whole Shandong province as a weight, calculate each pollutant's weighted average environmental value $\left(p_{j}\right)$ respectively, which is used as the key parameter to calculate the environmental value of resource saving and emission reduction caused by FEECEP of the whole province, as shown in Formula (29).

$$
P_{j}=\sum_{i=1}^{9}\left(\frac{Q P_{i, j} \times P_{i, j}}{\sum_{i=1}^{g} Q P_{i, j}}\right)
$$

$P_{j}$ is the weighted average environmental value per unit of $j$ pollutant emission reduction in Shandong Province; $Q P_{i, j}$ is the removal amount of the $j$ pollutant in city $i$ during the period from 2007 to 2015; $P_{i, j}$ is the weighted average environmental value per unit of emission reduction of the $j$ pollutant in city $i$; $i=1,2, \ldots, 9$, which represents 9 prefecture-level cities in Shandong Province, these cities have itemized data on the operating costs of disposal installations for every pollutant studied in this paper, and the other 8 cities lack this kind of data, so they will not be considered here.

\section{Accounting Method of Environmental Value of Resource Saving}

Formula (30) can be used to calculate the emission reduction of pollutants caused by resource saving.

$$
Q P_{i, c, t}=T Q E_{i, t} \times \alpha
$$

$Q P_{i, c, t}$ is the total amount of greenhouse gas emission reduction caused by government FEECEP in the $t$ period of city $i ; T Q E_{i, j}$ is the total amount of energy saving (the total amount of water saving when calculating ammonia nitrogen and COD) in the $t$ period of city $i, \alpha$ is the carbon dioxide emission factor per unit of standard coal and its value is $0.67 \mathrm{t} / \mathrm{tce}$ (ton/ton of standard coal equivalent) [20]. When calculating the environmental value of water saving, $Q P_{i, c, t}$ is the total amount of emission reduction of COD or ammonia nitrogen caused by government FEECEP in the $t$ period of city $i$; $\alpha$ is the concentration of COD or ammonia nitrogen per unit of industrial wastewater. According to the Integrated Wastewater Discharge Standard (GB 8978-1996), the highest allowable discharge concentration of chemical oxygen demand (COD) is $100 \mathrm{mg} / \mathrm{L}$, and that of ammonia nitrogen is $15 \mathrm{mg} / \mathrm{L}$.
Positive Externality Monetization Measurement Model

With the help of the econometric model parameters, this study calculates the positive externalities of industrial enterprises' relevant economic activities caused by government FEECEP in each prefecturelevel cities in Shandong Province in recent years. The calculation method is shown as Formula (31).

$$
E x_{i, t}=\sum_{j=1}^{6} T Q P_{i, j} \times P_{i, j}
$$

$E x t_{i, t}$ is the positive externality of industrial enterprises caused by the government FEECEP in the $t$ period of city $i$; TQP $P_{i, j}$ is the total emission reduction of the $j$ pollutant in city $i$, and its calculation method is the same as that of energy saving, which is shown as Formula (22) and Formula (23). $i=1,2, \ldots, 6$, which represents serial number of five industrial environmental pollutants, including sulfur dioxide, nitrogen oxide, smoke and dust, ammonia nitrogen, chemical oxygen demand, and the greenhouse gas carbon dioxide; $P_{i, j}$ is the environmental value per unit of emission reduction of the $j$ pollutant in city $i$.

The industrial positive externality scale $\left(\operatorname{SDE} x_{t}\right)$ of the whole Shandong Province caused by the government FEECEP is calculated as shown in Formula (32). $P_{j}$ is the environmental value generated per unit of emission reduction of the $j$ pollutant of Shandong Province.

$$
S D E x_{t}=\sum_{i=1}^{9} \sum_{j=1}^{6}\left(T Q P_{i, j} \times P_{j}\right)
$$

\section{Performance Evaluation Index of the Government FEECEP}

According to the connotation of internalization of externality, government should compensate the loss of the industrial enterprises' private benefits generated by implementing activities with positive externalities, which is equal to the part of enterprises' private benefits that is lower than the social benefits of this kind of activities, and the internalization degree of positive externality can be used as the evaluation standard of the performance of government FEECEP performance in the whole industrial system. Based on this idea, we construct a performance evaluation index, which is shown as Formula (33).

$$
E n p_{i}=\frac{\sum_{t=2011}^{t=2017} E x_{i, t}}{\beta \sum_{t=2011}^{t=2017} e c_{i, t}}
$$

$E_{n} p_{i}$ is the performance evaluation index of government FEECEP in city $i$ (which is also suitable for the performance evaluation of whole Shandong Province) from 2011 to 2017; $e c_{i, t}$ is the amount of this kind of expenditure in the $t$ period of city $i ; \beta$ is the proportion of government energy conservation and environmental protection funds invested in the 
industrial field. But this proportion has an obvious characteristic of spatiotemporally fluctuations, and the relevant data are difficult to obtain. Drawing on experience of the scenario analysis method, we assign five values in turn to parameter $\beta$ : $1,0.85,0.7,0.55$, and 0.4 in order to take into account the actual situation of different regions when evaluating the performance of government FEECEP.

If government FEECEP is regarded as a cost and positive externalities caused by this kind of expenditure as its benefit, the average income is equal to the average cost when the positive externalities of industrial enterprises' relevant activities are completely internalized, then the value of Enp ${ }_{i}$ should be equal to 1 .

According to the difference between the actual value of the performance evaluation index each year and 1, the performance of FEECEP is divided into five grades: that the value is bigger than 0.9 is high-efficient level, that 0.8 to 0.9 is good level, that 0.7 to 0.8 is medium level, that 0.6 to 0.7 is qualified level, and that less than 0.6 is inefficient level.

\section{Results and Discussion}

\section{Estimation Results of Econometric Models}

The panel data used in this study covers the data of 17 prefecture-level cities in Shandong Province from 2007 to 2017. Due to the lag effect of the third period, only eight years from 2010 to 2017 remain in the actual investigation period, which is a typical short panel. Because of the short investigation period and less information for each individual, it is impossible to discuss whether the error term has autocorrelation. Generally, it can be assumed that the error term is independent and identically distributed, so this study does not consider the autocorrelation of the models.

GMM (Generalized method of moments) of panel data would be more efficient when the number of instrumental variables is more than the number of endogenous explanatory variables [18]. This study considers employing the instrumental variable method to estimate the models. The estimation strategy revolves around the core explanatory variables and the explained variables, and adopts the method of

Table 13. Results of model estimation.

\begin{tabular}{|c|c|c|c|c|c|c|c|}
\hline Model & (2) & (3) & (4) & (5) & (6) & (7) & (8) \\
\hline Explanatory variable & LNenergy & LNh2o & LNemso & LNemnox & LNemand & LNemyan & LNemcod \\
\hline \multirow{2}{*}{ LNcomp1 } & $-0.2577 * * *$ & $-0.2117 * * *$ & $-0.8306^{* * *}$ & $-0.8481 * * *$ & $0.9792 * * *$ & $-0.3451 * * *$ & $-1.1950 * * *$ \\
\hline & $(0.0214)$ & $(0.0323)$ & $(0.1031)$ & $(0.1289)$ & $(0.0918)$ & $(0.1157)$ & $(0.0627)$ \\
\hline \multirow{2}{*}{ LNcomp2 } & - & $-0.0291 * * *$ & - & $-0.0681 * * *$ & - & - & - \\
\hline & & $(0.0039)$ & & $(0.0174)$ & & & \\
\hline LNcomp3 & - & - & - & - & - & - & - \\
\hline \multirow{2}{*}{ LNinin } & $-0.1428 *$ & & $-1.69813 * * *$ & $-2.0499 * * *$ & - & - & - \\
\hline & $(0.0795)$ & & $(0.3175)$ & $(0.4394)$ & & & \\
\hline \multirow{2}{*}{ LNgp } & - & $-0.0165^{*}$ & $0.07215 * *$ & - & $-0.0583 * *$ & $0.0737 * *$ & - \\
\hline & & $(0.0094)$ & $(0.0320)$ & & $(0.0288)$ & $(0.0355)$ & \\
\hline \multirow{2}{*}{ LNcf } & - & - & $2.0135 * * *$ & $1.9737 * * *$ & - & $2.0810^{* * *}$ & - \\
\hline & & & $(0.5814)$ & $(0.6522)$ & & $(0.6469)$ & \\
\hline \multirow{2}{*}{ LNhr } & $-0.1784 * *$ & - & - & - & $-0.5542 *$ & $-0.9872 * *$ & - \\
\hline & $(0.0872)$ & & & & $(0.3129)$ & $(0.3858)$ & \\
\hline \multirow{2}{*}{ IV } & LNlshra & LNlshra & LNlishui & LNlshra & LNlshra & LNlishui & LNlshra \\
\hline & LNcshou & LNcshou & LNcshou & LNcshou & LNcshou & LNcshou & LNcshou \\
\hline Centered $\mathrm{R}^{2}$ & 0.6442 & 0.4776 & 0.6955 & 0.7967 & 0.7278 & 0.2551 & 0.7647 \\
\hline $\begin{array}{l}\text { Cragg-Donald Wald F } \\
\text { statistic: }\end{array}$ & 577.81 & 443.773 & 107.202 & 54.155 & 450.503 & 506.472 & 788.624 \\
\hline \multirow{2}{*}{$\begin{array}{l}\text { Sargan statistic } \\
\text { p-value }\end{array}$} & 1.415 & 0.089 & 2.924 & 1.590 & 1.567 & 2.630 & 0.017 \\
\hline & 0.2343 & 0.7660 & 0.0873 & 0.2073 & 0.2106 & 0.1049 & 0.8972 \\
\hline
\end{tabular}

Annotation: The symbol "_- indicates the variables that have been eliminated from the model estimation. The numbers in parentheses are standard errors. The symbols *, **, and *** are significant at the level of $10 \%, 5 \%$ and $1 \%$. 
incorporating all the non-core explanatory variables at the beginning and then eliminating them in turn until the model parameters all are significant. In this study, three new variables generated from the two core explanatory variables and their third-order lag variables by the principal component method are used as main explanatory variables when estimating the models. The model assumes that there is only one endogenous explanatory variable, namely compl (containing 76\% of the information of two core explanatory variables). Two instrumental variables selected from the three alternative instrumental variables, which can pass the weak identification test and overidentification test of all instruments, are employed to participate in the model estimation. The regressions are executed by an unofficial Stata command named xtivreg2. The estimated results of the models are shown in Table 13 .

The $F$ statistics of the seven regression equations are far greater than 10 , indicating that the instrumental variables used in the model are strong instrumental variables [21]. Overidentification test is analyzed by the use of Sargan statistics [22]. The P value shows that only Model (4) rejects the null hypothesis at a significance level of $10 \%$. The other five models accept the null hypothesis. Namely, all instrumental variables are exogenous.

\section{Performance Evaluation of FEECEP of Shandong Province and its Prefecture-Level City}

Making use of the operating cost of pollutant disposal facilities of industrial enterprises and the amount of each pollutant removal during the investigation period in each prefecture-level city, the environmental value per unit pollutant reduction in Shandong Province and its nine prefecture-level cities were calculated, its values are shown in Table 14.
Industry is an important field of energy conservation and environmental protection, but there is no itemized expenditure data on government FEECEP. Therefore, the evaluation of performance of government FEECEP in industrial system can only be carried out by scenario analysis method. Industry is a major source of pollution and energy consumption, and government fiscal expenditures for energy conservation and environmental protection is bound to give priority to industry. This study sets up five scenarios, that is, assuming that industry accounts for $40 \%, 55 \%, 70 \%, 85 \%$, and $100 \%$ of this expenditure; the effects of RSPER caused by this expenditure will last for 10,15 and 20 years. At the same time, the effect of energy saving and pollutant emission reduction caused by this kind of expenditure is divided into two cases: only playing its role within the scope of the industrial scale of the current year and continuously playing its role within the scope of all subsequent industrial scales. According to the calculation method of the performance evaluation index of FEECEP, the performance evaluation index of Shandong Province and its prefecture-level cities from 2011 to 2017 can be obtained, as shown in Table 15-1. Since that the econometric model employs statistical principles to calculate the quantitative relationship between explanatory variables and explained variables of the research object over a certain period, it is of little significance for policy guidance to calculate the specific value of performance evaluation index of this kind of expenditure in every year, so the relevant calculations are omitted.

The research results show that, for Shandong province and Jinan City, the value of performance evaluation index can be confirmed as high efficiency only under certain conditions that $40 \%$ of government FEECEP has been expended in industrial system, the time that its effects work continuously with the growth

Table 14. The environmental value per unit pollutant reduction in Shandong Province and its nine prefecture-level cities.

\begin{tabular}{|c|c|c|c|c|c|c|}
\hline Pollutant & $\mathrm{SO}_{2}$ & Ammonia nitrogen & $\mathrm{NO}_{\mathrm{x}}$ & $\mathrm{COD}$ & Smoke and dust & $\mathrm{CO}_{2}$ \\
\hline Price & US\$/ton & US\$/ton & US\$/ton & US\$/ton & US\$/ton & US\$/ton \\
\hline Shangdong & 139.7763 & 1786.1316 & 668.3766 & 255.7254 & 11.8377 & 15.1766 \\
\hline Jinan & 212.6239 & 2177.3839 & 1461.2011 & 381.5392 & 26.8625 & 15.1766 \\
\hline Qingdao & 140.6869 & 2329.7567 & 485.0435 & 360.4438 & 11.0789 & 15.1766 \\
\hline Zibo & 142.8116 & 2583.6609 & 617.8386 & 383.9675 & 13.5072 & 15.1766 \\
\hline Zaozhuang & 83.6230 & 959.1598 & 316.7352 & 146.4540 & 5.1600 & 15.1766 \\
\hline Yantai & 111.5479 & 1912.8561 & 461.0645 & 265.7419 & 9.4095 & 15.1766 \\
\hline Weifang & 129.3045 & 1666.5402 & 641.3622 & 229.1664 & 9.8648 & 15.1766 \\
\hline Jining & 147.5164 & 999.8331 & 526.1720 & 218.2392 & 6.8295 & 15.1766 \\
\hline Tai'an & 99.1031 & 2508.3851 & 472.1434 & 328.7247 & 8.0436 & 15.1766 \\
\hline Rizhao & 247.6818 & 800.2610 & 1119.7280 & 114.7349 & 22.6131 & 15.1766 \\
\hline
\end{tabular}

Annotation: The price of carbon dioxide refers to the price of Beijing carbon emission market [23] 
Table 15-1. Performance evaluation Index of FEECEP of Shandong Province and Jinan city from 2011 to 2017.

\begin{tabular}{|c|c|c|c|c|c|c|c|c|c|}
\hline \multirow{2}{*}{ District } & \multirow{2}{*}{ Type } & \multirow{2}{*}{ Industry proportion } & \multicolumn{3}{|c|}{ Duration/year } & \multirow{2}{*}{ District } & \multicolumn{3}{|c|}{ Duration/year } \\
\hline & & & 10 & 15 & 20 & & 10 & 15 & 20 \\
\hline \multirow{10}{*}{ Shandong } & \multirow{5}{*}{ Stable scale } & $100 \%$ & 0.12 & 0.17 & 0.23 & \multirow{10}{*}{ Jinan } & 0.12 & 0.18 & 0.24 \\
\hline & & $85 \%$ & 0.14 & 0.21 & 0.27 & & 0.14 & 0.21 & 0.28 \\
\hline & & $70 \%$ & 0.17 & 0.25 & 0.33 & & 0.17 & 0.26 & 0.34 \\
\hline & & $55 \%$ & 0.21 & 0.32 & 0.42 & & 0.22 & 0.33 & 0.44 \\
\hline & & $40 \%$ & 0.29 & 0.44 & 0.58 & & 0.30 & 0.45 & 0.60 \\
\hline & \multirow{5}{*}{$\begin{array}{l}\text { Scale Increase pro- } \\
\text { gressively }\end{array}$} & $100 \%$ & 0.15 & 0.25 & 0.37 & & 0.14 & 0.25 & 0.38 \\
\hline & & $85 \%$ & 0.17 & 0.29 & 0.43 & & 0.17 & 0.29 & 0.44 \\
\hline & & $70 \%$ & 0.21 & 0.35 & 0.52 & & 0.21 & 0.36 & 0.54 \\
\hline & & $55 \%$ & 0.27 & 0.45 & 0.67 & & 0.26 & 0.45 & 0.68 \\
\hline & & $40 \%$ & 0.37 & 0.61 & 0.92 & & 0.36 & 0.62 & 0.94 \\
\hline
\end{tabular}

Annotation: Industry proportion refers to the share of government FEECEP expended in the industrial system; stable scale means that the effects of RSPER of this fiscal expenditure only play a role within the industrial scale of the current year; scale increase progressively means that the effects of RSPER can play a similar role with the growth of industrial scale. The duration is the time during which the positive externality caused by government FEECEP would continuously work. Limited by the availability of data, the value of performance evaluation index of Shandong Province is calculated using the data of energy conservation and pollutant emission reduction of nine prefecture-level cities, while the environmental values per unit pollutant emission reduction is calculated using 17 prefecture-level cities in Shandong Province.

Table 15-2. Performance evaluation index of FEECEP of prefecture-level cities in Shandong Province from 2011 to 2017.

\begin{tabular}{|c|c|c|c|c|c|c|c|c|c|}
\hline \multirow{2}{*}{ District } & \multirow{2}{*}{ Type } & \multirow{2}{*}{$\begin{array}{l}\text { Industry } \\
\text { proportion }\end{array}$} & \multicolumn{3}{|c|}{ Duration/year } & \multirow{2}{*}{ District } & \multicolumn{3}{|c|}{ Duration/year } \\
\hline & & & 10 & 15 & 20 & & 10 & 15 & 20 \\
\hline \multirow{5}{*}{ Qingdao } & \multirow{5}{*}{$\begin{array}{l}\text { Scale Increase } \\
\text { progress-ively }\end{array}$} & $100 \%$ & 0.15 & 0.25 & 0.37 & \multirow{5}{*}{ Zibo } & 0.16 & 0.26 & 0.37 \\
\hline & & $85 \%$ & 0.18 & 0.29 & 0.43 & & 0.19 & 0.30 & 0.43 \\
\hline & & $70 \%$ & 0.21 & 0.36 & 0.53 & & 0.24 & 0.36 & 0.52 \\
\hline & & $55 \%$ & 0.27 & 0.45 & 0.67 & & 0.30 & 0.46 & 0.66 \\
\hline & & $40 \%$ & 0.37 & 0.63 & 0.92 & & 0.41 & 0.64 & 0.91 \\
\hline \multirow{5}{*}{ Zaozhuanag } & \multirow{5}{*}{$\begin{array}{l}\text { Scale Increase } \\
\text { progress-ively }\end{array}$} & $100 \%$ & 0.06 & 0.11 & 0.16 & \multirow{5}{*}{ Yantai } & 0.07 & 0.12 & 0.19 \\
\hline & & $85 \%$ & 0.08 & 0.13 & 0.19 & & 0.08 & 0.14 & 0.22 \\
\hline & & $70 \%$ & 0.09 & 0.16 & 0.23 & & 0.10 & 0.17 & 0.27 \\
\hline & & $55 \%$ & 0.12 & 0.20 & 0.30 & & 0.13 & 0.22 & 0.34 \\
\hline & & $40 \%$ & 0.16 & 0.27 & 0.41 & & 0.17 & 0.30 & 0.47 \\
\hline \multirow{5}{*}{ Weifang } & \multirow{5}{*}{$\begin{array}{l}\text { Scale Increase } \\
\text { progress-ively }\end{array}$} & $100 \%$ & 0.16 & 0.26 & 0.37 & \multirow{5}{*}{ Jining } & 0.10 & 0.18 & 0.27 \\
\hline & & $85 \%$ & 0.18 & 0.30 & 0.44 & & 0.12 & 0.21 & 0.31 \\
\hline & & $70 \%$ & 0.22 & 0.37 & 0.53 & & 0.15 & 0.25 & 0.38 \\
\hline & & $55 \%$ & 0.29 & 0.46 & 0.68 & & 0.19 & 0.32 & 0.48 \\
\hline & & $40 \%$ & 0.39 & 0.64 & 0.94 & & 0.26 & 0.44 & 0.66 \\
\hline \multirow{5}{*}{ Tai'an } & \multirow{5}{*}{$\begin{array}{l}\text { Scale Increase } \\
\text { progress-ively }\end{array}$} & $100 \%$ & 0.04 & 0.06 & 0.09 & \multirow{5}{*}{ Rizhao } & 0.08 & 0.14 & 0.23 \\
\hline & & $85 \%$ & 0.04 & 0.07 & 0.11 & & 0.1 & 0.17 & 0.27 \\
\hline & & $70 \%$ & 0.05 & 0.09 & 0.13 & & 0.12 & 0.21 & 0.33 \\
\hline & & $55 \%$ & 0.06 & 0.11 & 0.17 & & 0.15 & 0.26 & 0.42 \\
\hline & & $40 \%$ & 0.09 & 0.15 & 0.23 & & 0.21 & 0.36 & 0.57 \\
\hline
\end{tabular}


Table 16. The structures of positive externality of industrial system in Shandong Province and its main prefecture-level cities.

\begin{tabular}{|c|c|c|c|c|c|c|}
\hline Area & COD & Ammonia nitrogen & Nitrogen oxides & Sulfur dioxide & Smoke and dust & Carbon dioxide \\
\hline Shandong & 0.04 & 0.02 & 0.37 & 0.08 & 0 & 0.48 \\
\hline Jinan & 0.05 & 0.02 & 0.49 & 0.13 & 0.01 & 0.30 \\
\hline Qingdao & 0.02 & 0.02 & 0.26 & 0.05 & 0 & 0.65 \\
\hline Zibo & 0.10 & 0.05 & 0.36 & 0.09 & 0 & 0.41 \\
\hline Zaozhuang & 0.05 & 0.02 & 0.23 & 0.09 & 0 & 0.62 \\
\hline Yantai & 0.05 & 0.01 & 0.31 & 0.08 & 0 & 0.55 \\
\hline Weifang & 0.04 & 0.03 & 0.36 & 0.13 & 0 & 0.44 \\
\hline Jining & 0.04 & 0.01 & 0.51 & 0.15 & 0 & 0.29 \\
\hline Tai'an & 0.03 & 0.02 & 0.32 & 0.06 & 0 & 0.56 \\
\hline Rizhao & 0.03 & 0.01 & 0.25 & 0 & 0.02 & 0.69 \\
\hline
\end{tabular}

of industrial scale could reach 20 years. This scenario can also apply to prefecture-level cities of Qingdao, Zibo and Weifang. Other prefecture-level cities can only be confirmed as qualified or inefficient even under same standards compared with three cities mentioned above. Therefore, we can generally conclude that the performance of FEECEP expended in industrial system of Shandong Province or its prefecture-level cities is relatively low (Table 15-2).

\section{The Structure of Positive Externality}

Different regions have different industrial structures, and different industrial structures result in different pollutant components in regional industrial wastewater and industrial waste gas, which means that the main tasks of energy conservation and pollutant emission reduction in different regions are different, that is, government fiscal expenditure structures for energy conservation and environmental protection have regional differences. Figuring out the positive externality structure is of great significance for optimizing government fiscal expenditure structure for energy conservation and environmental protection, and thereby improving the performance of energy conservation and environmental protection funds. Positive externality structures of industrial system in each prefecture-level city can also be obtained when the effects of RSPER and the industrial positive externality scale measured in currency are worked out. The data are shown in Table 16.

The results of the study show that the positive externality of industrial system measured in currency in Shandong Province and its prefecture-level cities is mainly composed of three parts: the environmental values of carbon dioxide emission reduction, nitrogen oxide emission reduction, and sulfur dioxide emission reduction. The environmental value of carbon dioxide emission reduction plays an absolutely dominant role in the positive externalities. The proportion of the Shandong Province is $48 \%$, the city with the highest proportion is Rizhao, which reaches $69 \%$, and the city with the lowest proportion is Jining, which also reaches $29 \%$. Secondly, the environmental value generated by NOx emission reduction accounts for a high proportion of positive externalities; for the entire Shandong Province, this proportion reaches 37\%. The environmental value of sulfur dioxide emission reduction ranks third, which is much lower than the former two, indicating that the government fiscal expenditure for energy saving has not achieved an obvious effect of sulfur dioxide emission reduction. This is far from the people's subjective impression that the government has done a lot of work to reduce emissions of this pollutant. There may be two reasons. One is that the share of fiscal expenditure for desulfurization is very low, and the other is that there may be a problem of inefficient use of funds. The relevant mechanism needs to be further studied. The environmental value of the other three pollutants emission reduction accounts for a small proportion of the positive externalities, especially smoke and dust, which accounts for close to zero. The low proportion of the emission reduction of COD and ammonia nitrogen in positive externalities measured in currency reveals a fact that the share of FEECEP used to strengthen industrial wastewater disposal in the past decade is not high, which is highly consistent with the situation reflected in Table 4.

\section{Conclusions}

To sum up, this study gets the following conclusions:

(1) The internalization degree of positive externalities is a suitable indicator for evaluating the performance of government expenditures for energy conservation and environmental protection. Judging from the performance evaluation index of Shandong's fiscal energy conservation and environmental protection expenditure, the issue that needs attention in energy 
conservation and environmental protection is not just how to increase investment, the more important issue that makes this kind of expenditure better play the role of RSPER is how to completely internalize the industrial positive externalities caused by this fiscal expenditure, that is, how to improve the performance of this kind of fiscal expenditure. This is an issue that is generally ignored by academia and government functional departments in practice. If we do not correct the concept in time and greatly increase the scale of this expenditure, the general method of work that obtains the effect of RSPER by increasing fiscal expenditure in this field would reduce the efficiency of the market allocation of social resources because the government has invested too many resources although the governmental goal of RSPER will also be achieved.

(2) The environmental value generated by unit pollutant emission reduction or unit resource saving plays a key role in the performance evaluation of government FEECEP. The performance evaluation index of FEECEP is closely related to the estimation of environmental value generated by the emission reduction of unit pollutants. The latter has always been a controversial topic, and there is a huge gap between the environmental values of pollutant emission reduction given by different scholars. For example, theoretically speaking, that taking the quotient of annual operating cost of desulfurization facilities and the annual removal of sulfur dioxide as the environmental value of unit sulfur dioxide emission reduction should be an underestimation. The parameters obtained in this way are only the operating costs of desulfurization facilities to remove sulfur dioxide under the current technical level, which is a different concept compared with the environmental loss caused by the same amount of sulfur dioxide discharged into the atmosphere. It is the key link to improve expenditure performance to reasonably determine the environmental value generated by pollutant emission reduction and resource saving.

(3) The statistical system in the field of environmental protection expenditure in China has yet to be improved. The FEECEP has been listed separately in the national finance only since 2007. In terms of this expenditure, the relevant statistical system has not been fully established. For example, the detailed data of this expenditure in every industrial sector should be included in the relevant statistical system, so that government and researchers can obtain more sufficient information, so as to create more favorable conditions for optimizing the expenditure structure and improving the expenditure's performance.

(4) There are huge spatial differences in the environmental value of pollutant emission reduction. Taking the environmental value per unit of nitrogen oxide emission reduction as an example, Zaozhuang is only equivalent to less than a quarter of Jinan, and Qingdao and Taian are equivalent to approximately one third of Jinan. This shows that it is very inaccurate to ignore the regional differences in the environmental value of pollutant emission reduction to evaluate the performance of government FEECEP. The current research on the performance evaluation of government FEECEP based on China's provincial panel data using DEA method should take the environmental value of pollution reduction into account.

The deficiency of this study is that the evaluation model involves many parameters, and the economic environment on which the calculation of the parameter values depends has a large uncertainty, which to a certain extent makes the evaluation results also have a large uncertainty. For example, the period during which the effect of energy saving and pollutant emission reduction of enterprises' positive externalities will continue to play a role, this study employs scenario analysis method to calculate the scale of positive externalities measured by monetization under the conditions of 10, 15 and 20 years. In reality, this period should have a more accurate value. How to make these parameters more in line with the actual conditions of economic operation is a problem that needs to be addressed in the next step of this research.

\section{Acknowledgment}

This study was funded by the Shandong Provincial Natural Science Foundation, China (ZR2021MG040), Shandong Provincial Humanities and Social Project, China (2021-JCGL-01) and Key deployment projects of Innovation Academy for Green Manufacture, Chinese Academy of Sciences (IAGM-2019-A16). We also thank the administrative bureaus of prefecture-level cities in Shandong province for their assistance in data collection.

\section{Conflicts of Interest}

The authors declare no conflict of interest.

\section{References}

1. ZHANG T.F., YANG J. Efficiency Evaluation and Policy Matching of Environmental Protection Fiscal Expenditure on Green Development. Reform. (5), 60, 2019.

2. ZHANG K.Q. Environmental Fiscal Expenditure and Pollution. Urban and Environmental Studies. (4), 94, 2018.

3. CHEN Z.Y., XIN C.C. The Measurement and Evaluation of the Non-equilibrium of Public Environmental Expenditure in China. Research on Economics and Management. 38, (10), 82, 2017.

4. JIANG N. Will environmental spending help achieve a win-win situation for the economy and the environment? Journal of Zhongnan University of Economics and Law. (1), 95, 2018.

5. ZHANG Y. Research on Environmental Governance Effects of China's Fiscal and Taxation Policy: Empirical 
Analysis Based on Provincial Panel Data. On Economic Problems. (10), 43, 2016.

6. ZHU X. H., LU Y. Q. Pollution governance effect on environmental fiscal and taxation policy:based on region and threshold effect. China Population Resources and Environment. 27, (1), 83, 2017.

7. ZANG C.Q., CHEN M. Performance Analysis of Fiscal Expenditures on Environmental Protection - Based on the Panel Data of 30 Provinces of China in 2007-2015. Finance \& Economics. (6), 68, 2018.

8. WOOLDRIDGE J.M., Introductory Econometrics: A Modern Approach, Fifth ed.; China Renmin University Press: Beijing, China, 2015.

9. WU Y. Research on the Environmental Protection Fiscal Expenditure Effect and Efficiency of the Local Governments in China. Doctoral Dissertation, Liaoning University, 64, 2017.

10. WANG Q., LI C. A Study on Efficiency Evaluation of Fiscal Expenditure on Environmental Protection and its Influential Factors in China. East China Economic Management. 32 (7), 102, 2018.

11. WAN J.X. Performance Analysis of China's Fiscal Budget Expenditure on economic growth, resource consumption and environmental protection. Public Finance Research. (3), 6, 2015.

12. PAN X.Z. Efficiency Analysis of China's Local Government's Expenditure on Environmental Protection. China Population Resources and Environment. 23 (11), 61, 2013.

13. BANKER R.D.,CHARNES A., COOPER W.W. Some Models for Estimating Technical and Scale Inefficiencies in Data Envelopment Analysis. Manage. Sci. 30 (9), 1078, 1984

14. WANG J., PAN Y. Evaluation of Shandong Fiscal Expenditure Efficiency for Local Environmental
Protection. Journal of Shandong University of Finance and Economics. 29 (6), 43, 2017.

15. ZHU H., FU Q., WEI Q. Calculation of Efficiency on Environmental Expenditure and Study on Influential Factors. China Population, Resources and Environment. 24 (6), 91, 2014.

16. SUN J., MA H., WANG H. Fiscal Decentralization,Policy Synergy and Efficiency of Air Pollution Governance analysis Based on the Panel Data of Urban Agglomeration in Beijing-Tianjin-Hebei and the Surrounding Areas. China Soft Science. (8), 154, 2019.

17. WANG Q., Data Envelopment Analysis Method and Convex Polyhedron Technology.; China Social Sciences Press: Beijing, China, 3, 2018.

18. CHEN Q., Advanced econometrics and Stata application, Second ed.; Higher Education Press: Beijing, China, 257, 2014.

19. DONG Z.G., ZHAO W., ZHOU X., ZHAO P.L. Analysis of treatment cost of urban wastewater treatment plant on Chemical oxygen demand and Ammonia Nitrogen. Environmental Protection and Circular Economy. (10), 67, 2017.

20. BAI L.T. Energy Saving Handbook 2006, 1st ed.; Magazine of Energy Conservation \& Environmental Protection: Beijing, China, 137, 2006.

21. WU Y.W. Searching for the Archimedes' Lever: Is Quarter-of-Birth Really A Weak Instrumental Variable? China Economic Quarterly. 9 (2), 661, 2010.

22. ROODMAN D. How to do xtabond2: an introduction to difference and system GMM in Stata. Stata. J. 9 (1), 86, 2009.

23. LI Z. X., ZHANG X.J., DONG Y. Research on China's Carbon Emissions Trading Market Status, Problems and Measures. Ecology and Environmental Sciences. 23 (11), 1876, 2014. 